Article

\title{
Factors Influence China's Off-Site Construction Technology Innovation Diffusion
}

\author{
Yudan Dou ${ }^{1}$, Xiaolong Xue ${ }^{1,2}$, Zebin Zhao ${ }^{1, *}$ and Xiaowei Luo ${ }^{3}$ (i) \\ 1 School of Management, Harbin Institute of Technology, Harbin 150001, China; douyudan@hit.edu.cn (Y.D.); \\ xlxue@hit.edu.cn (X.X.) \\ 2 School of Management, Guangzhou University, Guangzhou 510006, China \\ 3 Department of Architecture and Civil Engineering, City University of Hong Kong, Hong Kong 999077, \\ China; xiaowluo@cityu.edu.hk \\ * Correspondence: zhaozebin@hit.edu.cn
}

Received: 16 January 2019; Accepted: 20 March 2019; Published: 27 March 2019

check for updates

\begin{abstract}
Technology innovation is a key to Off-Site Construction (OSC), but it can achieve economic and social benefits through diffusion. Previous research mainly focused on the optimization or on-site applications of OSC technology innovation; little on its diffusion-related analysis. Diffusion performance generally leads to a faster and deeper diffusion of OSC technology innovation. To study what influence the diffusion performance of OSC technology innovation, the authors first determined the research border and proposed four hypotheses, and then conducted a questionnaire in various China's construction companies. After investigating 119 construction companies for three months, 151 valid responses were collected and analyzed using Hierarchical Regression and bootstrap-based mediation test approaches. The results found that both market and government had significant impacts on the diffusion performance with comparable influence degree $\left(0.282^{* *}\right.$ and $\left.0.255^{* *}\right)$, the government played a dual-mediating effect with network power simultaneously (effect value is 0.215$)$ and the technical versatility had a significant indirect influence $\left(>0.204^{* *}\right)$ but weak direct impact (0.094) on the diffusion performance of OSC technology innovation. The conclusions explored the influence mechanism of different factors on the diffusion of OSC technology innovation and provided practical suggestions for both construction companies and government authorities to promote the development of OSC.
\end{abstract}

Keywords: diffusion performance; dual-mediating; moderated mediating; technology innovation; off-site construction

\section{Introduction}

Sustainability is a focus issue worldwide [1-3]. China is a major carbon emitter and the construction industry is one of the main sources of carbon emissions in China [4,5]. In addition, China has a large population (1.39 billion people as of the end of 2017), resulting in a great housing demand. Additionally, winter construction is common in most regions in China, leading to the costs increase because of the long construction period. Therefore, exploring a sustainable and short-period construction form is inevitable in China. Off-Site Construction (OSC) is considered to be a solution for the housing crisis and unsustainable construction [6-9]. The advantages of OSC include the reduction of rework and on-site injuries, the improvement of construction quality and the increase of productivity $[10,11]$, which are beneficial to economic and social sustainability. Furthermore, successful practices of OSC can reduce noise pollution and carbon emissions [4,11], which contributes to environmental sustainability. However, compared with the on-site mode, OSC also has disadvantages of poor structural integrity, poor stability and poor earthquake resistance [5], [12]. It should be 
compensated by technical means to ensure the safety of the structure. Therefore, technology innovation to address those disadvantages is the key to the more successful and broader implementation of OSC [5,9]. Some developed countries have mature experience in the theories and practices of the Off-Site Construction Technology Innovation (OSCTI) [7,13]. These mature technology innovations will exert economic benefits only through diffusion $[14,15]$ and then promote the development of OSC significantly. The research on the diffusion of technology innovation make much sense [16].

At the current stage, China's OSC is still in its exploratory stage of development, with an insufficient capacity for OSCTI and the underdeveloped supply chain $[9,11,17]$, especially the challenges that through mature technologies could not be effectively diffused [5]. The whole industry needs to strengthen the Research and Development (R\&D) ability of OSCTI and to diffuse the mature technology innovation to the market efficiently. To realize the effective diffusion of OSCTI, it is first necessary to clarify three questions: what influences the diffusion? How do they influence the diffusion? What are the influence degrees? Therefore, the research of the factors influencing the diffusion of OSCTI and their influence mechanism are inevitable. However, it is difficult to clear research borders and collect empirical data. Firstly, the authors determined the influencing factors of the diffusion of OSCTI as the external environment, the diffusion subject and the diffusion object from the composition of technology innovation diffusion system [18]. For data collection, the authors made full use of various channels such as project cooperation, work partners, telephone calls, emails and field interviews. As for the construction companies, if the diffusion performance (including economic performance, environmental performance and social performance) of OSCTI increase, they will tend to adopt or supply (called "diffuse") OSCTI [19], to promote the diffusion of technology innovation [20]. Therefore, this paper uses "Diffusion Performance" (DP) to represent the diffusion effects of OSCTI.

The objective of this paper was to deeply analyze the impacts of different factors on DP of OSCTI and their influence mechanism and interrelations. Specifically, the authors will demonstrate the influence factors and theory analysis from three dimensions: external environment, diffusion subject and diffusion object, which constitute the core components of the technology innovation diffusion system. Based on this, a conceptual model with four hypotheses will be proposed. Then, the authors conducted an empirical analysis through the data obtained from questionnaires and field interviews in construction industry level in China, using Hierarchical Regression and bootstrap-based mediation tests approaches, and concluded that: (1) the market and the government have significant and similar impacts on DP; (2) the government plays a dual-mediating effect with company feature simultaneously; (3) the technology innovation characteristic plays a significant moderated role in the relationship between the market and DP, but has weak direct impact on DP; (4) the government and company feature also play moderated mediating effects under different levels of technology innovation. The results provide corresponding suggestions for both construction companies and governments.

\section{Literature Review}

At present, the level of China's OSCTI is low, and there are few independent innovations while most are introduced by developed countries [5]. Moreover, the technical standards are immature, and the cost-saving ability brought by technology innovation is insufficient, resulting in the government-driven state with passive acceptance of construction companies in China. As the diffusion of OSCTI, an increasing number of construction companies enter the OSC industry. Then technology costs gradually reduce while technology ability improves, and the OSC market will become healthy and orderly. Hence, to achieve rapid development of OSC, the effective diffusion of mature OSCTI is necessary.

The diffusion of technology innovation is a process of disseminating the technology innovation among members in a certain social system in a certain time and through certain channels [15]. Construction technology innovation spans through the entire industry supply chain [21-24]. For example, the Computer Aided Design (CAD) technology, widely used in the construction industry, has applications in most parts of the construction supply chain, and is an important technology 
innovation in the implementation of construction. The importance of OSCTI in achieving construction sustainability is significant, but the research on OSCTI mainly focused on the technology innovation optimizations or on-site applications [25-31]. Few studies worked on the diffusion of OSCTI and the influence mechanism of various factors [32-36].

The adoption or supply (called "diffusion") of a certain technology innovation by construction companies is a complicated process influenced by external and internal influence factors [37,38]. Slaughter (1998) found that external environment, such as construction conditions, played an important role in diffusion [39]. Toole (1998) found that decisions of innovation adoption relied on external stakeholders [40]. Beise (2004) found that the primary driving force of technology innovation diffusion was the market [41]; thus, the companies should fully utilize the lead market to adopt and promote technology innovation. Suprun (2015) found that the financial subsidies and policy incentives were the most critical strategies for the diffusion of construction technology innovation [42]. Vastag (2010) found that the diffusion of ISO 14000 was influenced by the number of government-approved environmental treaties [43]. Previous studies have emphasized the impact of market or government on the diffusion of technology innovation, but few considered the two impacts simultaneously and compared their respective influence degree. Additionally, much research focused on the direct impacts, with little attention to the indirect impacts of market or government on innovation diffusion, such as the mediating effect.

Some studies have shown that the diffusion of technology innovation is mainly driven by the strength of the company [35,44]. Mansfield (1977) found that the richer experience and stronger capabilities a company had, the stronger incentive to accept new technologies it would have [45]. The network effects also influence the diffusion of technology innovations [46]. Opinion leaders affect the diffusion difficulty of technology innovation in diffusion networks [47]. In addition, Rogers's diffusion model of innovation [15] showed that the innovation characteristics, such as relative superiority and technological complexity, were important factors for diffusion. Previous research found that internal factors had significant impacts on the diffusion of technology innovation; however, they paid more attention to the direct impacts on the diffusion of technology innovation, while being less focused on the indirect impacts under different contexts, such as mediating or moderating effects.

To sum up, few studies worked on the deep analysis of the influence factors and mechanism of the diffusion of OSCTI, especially from the composition perspective of technology innovation diffusion system. Some research concentrated on both market and government and their respective influence degree, but little focused on the indirect impacts of government and the characteristics of diffusion subjects and diffusion objects on DP of OSCTI, and even less on the complex analysis of moderated mediating effects. Therefore, this study tried to fill this gap by empirical analysis of OSCTI implemented in China.

This study analyzed the influencing mechanism and influence degrees of the key factors affecting the diffusion of OSCTI, from the perspective of the three components of the technology innovation diffusion system. A conceptual model of the influence of external environment, diffusion subject and diffusion object on DP of the OSCTI with four hypotheses was proposed, taking China's construction companies as the research subjects. The authors conducted an industry-wide survey of OSC in China using a questionnaire and field interview. The data was analyzed using Hierarchical Regression and Bootstrap-based mediating tests methods. Results provided quantitative supports for China's construction companies to make decisions for the diffusion of OSCTI and helped government authorities to developing proper measures for policies.

\section{Theory and Hypotheses}

The external environment that influences the diffusion of OSCTI mainly includes the environment of market and policy, and their influence modes are reflected in Market Regulation (MR) and Policy Intervention (PI) separately. Moreover, Network Power (NP) and Technical Versatility (TV), as the critical strength manifestation of a construction company [46] and characteristic of an OSCTI [5,48], 
are extracted to represent the diffusion subjects (construction companies) and the diffusion objects (OSCTIs) respectively in this study.

As mentioned above, the diffusion of OSCTI is regulated by the external environment (both the market and the government), and the diffusion subject (strength of the construction company) and the diffusion object (characteristics of OSCTI) also play important roles. How do these factors influence DP of OSCTI? What is the relationship between different factors? These the key questions to answer in this study. Based on this, relevant theory analysis and research hypotheses are proposed next.

\subsection{External Environment}

\subsubsection{Market Regulation}

Business activities of any organization are inseparable from the market. Its survival and performance are usually dependent on the relationship with other organizations [49]. The theory of technology innovation diffusion holds that market environment plays a significant role in the diffusion speed of technology innovation [18]. Stakeholder Theory believes that companies can maximize their interests through the interaction with other companies, including cooperators and competitors [50]. Studies have shown that MR is mainly reflected in the adjustment of cooperation and competition between companies [51,52]. MR can promote the sustainable growth of companies' sales and profit levels. Besides, efficient cooperation and healthy competition because of proper MR can bring marketing innovation, reduce the operation costs and eventually promote the development of new markets [53].

With the promotion of OSC, the construction company continuously interact with other companies through cooperation and competition to form networks, supporting knowledge and technology sharing [54]. The diffusion of OSCTI will be achieved through knowledge spillovers and technology transfer. In market activities, other companies closely related to the construction company include both cooperative and competitive companies. Previous studies believed that the feasibility of OSC heavily relied on collaboration among the companies [55]; thus, MR was a key influencing the diffusion of OSCTI. Firstly, the construction company acquires equipment, materials or management models for OSC through vertical cooperation with suppliers. When an increasing number of suppliers respond to the government calls to produce prefabricated equipment and components, the construction companies will feel confident in the profit from OSCTI because of optimistic market status [5]. Therefore, to a large extent, the construction companies are guided to use the OSC products, and OSCTI will be diffused. On the other hand, the horizontal cooperation between the peer companies, such as cooperation between the developers or the component manufacturers, can realize the complementarity of capital, professional knowledge, talents and management in OSCTI [56]. Therefore, comparing to respective R\&D and implementation of OSCTI, the diffusion costs and capital risks related to OSCTI can be reduced through cooperation, to promote the diffusion of OSCTI. Conversely, if the number of cooperators is small or the cooperation between companies is poor, the construction company cannot obtain OSCTI information and resources timely, leading to the diffusion failure of OSCTI [17]. Collaboration between companies is also reflected in the competition [36]. The interaction between the competitors drives the construction companies' close attention to the competitor's OSCTI achievements and draws on their advanced technologies, to continually improve their technical systems and management models and enhance DP of technology innovation. Benign competition is a critical manifestation of good market regulation [56], which directly influences the diffusion effect of OSCTI. Therefore, MR can promote the diffusion of OSCTI through guiding cooperation and competition between companies.

\subsubsection{Policy Intervention}

Institutional theory believes that institutional environment is a crucial factor influencing companies to change their economic and social activities [57]. At the current stage, the development 
of China's OSC is that social and environmental benefits outweigh economic benefits [11], requiring construction companies to diffuse OSCTI instead of pursuing short-term economic benefits. However, this is difficulty for companies that are profitable. Therefore, the government will play a market-guided role by issuing proper policies. Public policies may accelerate or hinder the diffusion and further influence the depth and effectiveness of diffusion $[58,59]$. The government intervenes the market through administrative means, mainly PI [60], to adjust the allocation of innovations in the market [61] and to reduce the uncertainty of innovation diffusion [62].

PI is significant in the diffusion of OSCTI especially because of immature development of OSC in China. There exist problems such as high input costs, incomplete technical systems and inadequate diffusion of mature technologies [5]. Meanwhile, the inconspicuous short-term economic benefits of implementing OSCTI lead to the low initiative of construction companies for diffusing OSCTI. The market cannot entirely drive the technology innovation and its diffusion at the current stage in most regions in China [5]. However, as the environmental and social benefits of OSC are enormous towards the goal of construction sustainability [9], the government has vigorously promoted the OSC from top to bottom. Therefore, the implementation of OSC has been raised to the national level in China.

According to institutional theory, institutional pressure includes regulatory pressures, normative pressures and imitation pressures [63]. In the current policies of OSC issued by China's government, they are reflected by compulsory policy and incentive policy. Compulsory policies, such as restricting the prefabrication rate and supporting the land use for prefabrication, have been implemented to promote OSC. These policies urge the construction companies to carry out OSC for the acquisition of land, and thereby, OSCTI is diffused. Besides, the government supports the construction companies through many incentive policies, including additional funding for OSC, scientific research supports and rapid approval services related to OSC. Then, the costs and risks associated with OSCTI diffusion for the construction companies are reduced, to stimulate the diffusion of OSCTI. Therefore, whether it is a compulsory policy or incentive policy from the government, PI will promote the diffusion of OSCTI.

Many previous studies have suggested that MR and PI play important roles in the diffusion of technology innovation $[5,11,17]$. In mature markets, the government generally weakens PI and the diffusion of technology innovation will be dominated by MR. However, in the current stage of OSC development in China, the OSCTI market is far from complete and the market cannot achieve self-regulation, which forces the government to strengthen administrative measures to support the advancement of OSCTI. Therefore, the impact of PI on DP of OSCTI is highlighted, and may be comparable to the role of MR when considering the average level including both developed and undeveloped regions nationwide.

Based on the analysis above, the following hypothesis is proposed.

Hypothesis 1 (H1). External environment, including both MR and PI, has a significant positive impact on DP, and they may have similar influence degrees.

The cooperation and competition among construction companies by MR exist in parallel with PI, which are the dual means by market and government to promote the diffusion of OSCTI. Moreover, the cooperation and competition relationships by the market also influence policies issued by the government [64]. Good cooperation and competition relations regulated by MR indicate the strong strength and significant influence of construction companies in its industry. As a result, the government tends to open its subsidy policy of OSCTI to the construction companies, which can improve the approval efficiency of matters related to OSC for the construction company. Additionally, the government is more inclined to invite those construction companies that can use their excellent professional knowledge, high prestige and discourse power in the industry to improve the OSCTI system, to participate in the regulation development for OSC, technical specifications and related 
standards. Therefore, DP of OSCTI can be quickly and effectively promoted. The OSC-related policies are generally adjusted based on the current market environment [5]. The cooperation and competition between companies by market regulation directly influence policy orientation, and further influence the diffusion effect of OSCTI. That is, the influence of MR on DP (at least in part) plays a role through PI. Based on the analysis above, the following hypothesis is proposed.

Hypothesis 2 (H2). PI has a significant mediating effect on the relationship between MR and DP, that is, the influence of MR on DP (at least in part) plays a role through PI.

\subsection{Network Power}

Construction companies are the diffusion subjects of OSCTI, and also the targets of MR and PI. Therefore, the feature of a construction company (especially the company strength) affects the diffusion of OSCTI. The good cooperation and competition regulated by the market is the embodiment of the company strength [56]. The more powerful companies in the market indicate the better effect of MR. In practice, the companies with strong strength usually participate in the formulation of industry standards and related policies, which can capture policy orientation faster, to improve strength further.

Social networks are spread throughout our social and economic life, and social network theory has been widely used [65-67]. In the network environment, the construction companies will be actively or passively embedded in various complex networks [46], including the diffusion networks of OSCTI. According to the Resource Dependency Theory (RDT), the resource dependency relationship between any two companies in the network will result in the power of one company over the other one. This kind of power generated by resource dependence, called Network Power (NP), will adjust the control and influence of the company on other companies in the network [68]. The control of one company over the others can constrain the others' behaviors and thereby form the norms in the network, which can adjust the diffusion degree of technology innovation. Moreover, a company's influence over others will strengthen the cooperation between the companies. NP is an external manifestation of the overall strength of a company [69].

As an important feature of construction companies (diffusion subjects), NP has a significant impact on DP of OSCTI. The construction company with different NP will have different opportunity to acquire OSCTI. The companies with higher NP have stronger control and influence over others in the network. The more advanced technology and knowledge resource a company has, the greater NP it owns, making the company easier to become a leader in the network. When adopting an OSCTI, the leading company can lead the peripheral companies with lower NP spontaneously to follow its adoption behavior, thus achieving the diffusion of OSCTI. Furthermore, companies with greater NP usually have higher prestige and stronger voices, and they intervene with other companies in formal/informal and explicit/implicit forms [70]. Those companies promote some OSCTI diffusion through developing unified technical systems. At the same time, companies with greater NP can build a power base through technology alliances, increase the pressure on competitors [71], and improve DP of OSCTI. Therefore, the construction companies with greater NP will get higher DP of OSCTI, which can promote the diffusion of OSCTI.

On the other hand, optimization of MR can develop and improve diversified cooperative relationships, help the construction companies to gain the trust and recognition from their partners, further stabilize the established cooperative relationships and promote the construction companies to attract more partners with high-tech and high-quality products for cooperation. Strengthening the interaction between the construction companies and others can facilitate them to have a deeper understanding of cooperation, and to build technology and strategic alliances to expand the market influence. Furthermore, the better MR makes the construction company to be easier to acquire the information of latest OSCTI promptly. With the latest information, the construction companies can achieve complementary advantages, update and improve the technical system and finally make impacts on the competitors and gain more profits. Therefore, better MR can improve the overall 
strength (that is NP) of the companies, and then increase DP of OSCTI. That is, the impact of MR on DP is partly through NP. The influence of PI on NP is complicated. Simply concluding that the more PIs make the companies be stronger (or weaker) is unreasonable. The significance of PI on NP is related to many factors, such as government attitude and support or suppress. Therefore, it is difficult to predict whether the impact of PI on DP will partially through NP.

Based on the analysis above, the following hypotheses are proposed.

Hypothesis $3(\mathrm{H} 3)$. NP has a significant impact on DP and plays a significant mediating effect on the relationship between MR and DP, that is, the direct and indirect impacts of NP on DP are both significant.

\subsection{Technology Versatility}

Technology innovation is the object of the innovation diffusion, the characteristics of technology innovation have an important influence on its diffusion, affecting whether companies adopt it or not [15]. Technology innovation characteristics [48], including the relative advantages, compatibility and complexity, determine the speed and depth of technology diffusion [5]. TV is an important aspect of the characteristics of OSCTI and a key element that reflects the maturity of OSCTI development [59].

The high versatility and low complexity of OSCTI mean that the tacit knowledge involved is less, reducing the costs of technology acquisition and management and the risk of technology adoption [72]. Increasing the versatility and reducing the complexity of OSCTI can, therefore, lower the OSC market-entry barrier. The development of on-site construction with a generic system of technology and standards is relatively mature, while few technical systems of OSCTI have just been formed [11], and its scale production and scale benefits cannot be achieved [5,17]. TV contributes to the establishment of generic technology and standards systems, increases the number of companies applying OSCTI and promotes its diffusion. Moreover, different systems have different sources of technology innovation, while the high compatibility makes transmission and replication costs between systems low, increasing the expected profits of construction companies and promoting the development of OSC. In other words, TV has a positive effect on DP of OSCTI.

Additionally, technology innovation cannot reach the extent from the rough to the perfect and from the minority to the general industry-wide use without the cooperation and competition among the companies in the market [64]. Whether it is self-developed innovation or introduced innovation from others, the construction companies need to complement advantages through cooperation and improve the competitiveness to adapt to the market demand and increase the efficiency of technology diffusion. The close cooperation between the construction companies and other companies facilitates them to get new technologies and new knowledge in different fields [6]. At this time, high TV can simplify the acquisition of new knowledge and new technologies [73], improve efficiency, reduce costs and accelerate the diffusion of technology innovation. In comparison, low TV will increase the difficulty and costs of understanding and using the new technology and knowledge and reduce efficiency, which is harmful to the diffusion of OSCTI. Therefore, the higher TV is, the more significant the impact of MR on DP of OSCTI is. That is, TV positively adjusts the relationship between MR and DP.

Based on the analysis above, the following hypothesis is proposed.

Hypothesis 4 (H4). TV has a positive impact on DP and plays a significant moderating effect on the relationship between $M R$ and DP, that is, the direct and indirect impacts of NP on DP are both significant.

\subsection{Conceptual Model}

According to the analysis above, the dual regulations of market and government can promote the balance the short-term benefits and the long-term benefits of OSCTI, and achieve its sustainable diffusion. The construction companies feature (represented by NP) and the OSCTI characteristics (represented by TV), as the diffusion subjects and object respectively, influence DP of OSCTI, 
and play different indirect roles in the relationship between MR and DP. Therefore, the authors summarized a conceptual model of the influence of different factors on DP, as Figure 1. Specifically, external environment (including both market regulation and policy intervention, i.e., MR and PI) has a significant positive impact on diffusion performance (DP), with a similar influence degree of MR and PI (Hypothesis 1, H1). PI plays a significant mediating role in the relationship between MR and DP (Hypothesis 2, H2). Network power (NP) has significant positive impact on DP and mediating effect in the relationship between MR and DP (Hypothesis, H3). Technical versatility (TV) has significant impact on DP and moderating effect in the relationship between MR and DP (Hypothesis 4, H4).

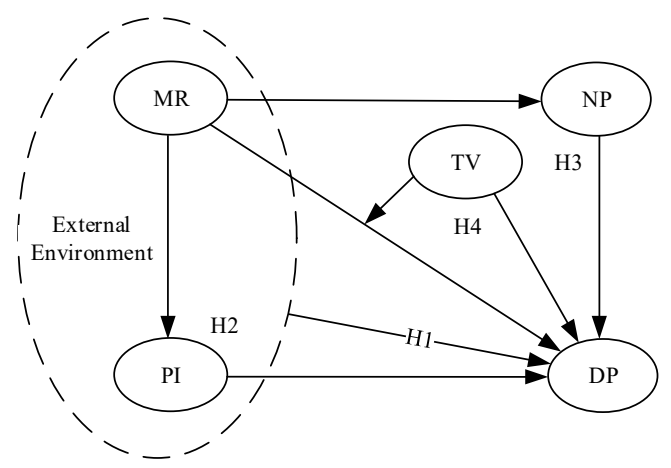

Figure 1. Conceptual Model of the Impacts of Different Factors on DP of the OSCTI.

\section{Methodology}

\subsection{Empirical Analysis Method}

The questionnaire method is one of the most popular methods in the current management quantitative research [74]. The proper implementation can accurately transform the research objectives to the specific problems, to get high-quality research results with low costs [75].

The survey process of the questionnaire in this study is divided into six stages. at first, the border of sampling was confirmed: (1) the survey targets were the construction companies professionally or partially using OSCTI in different regions in China, including developers, consultants and designers, construction contractors, component manufacturers and decorators, etc.; (2) the respondents were mainly targeted at senior and middle managers responsible for OSCTI adoption, as well as technicians and R\&D personnel, excluding field workers; (3) the sampling period was three months, from 2018/05-2018/08. Next, the authors collected rough information of construction companies on the Internet, professionally or partially using OSCTI. Then, the authors identified the companies that can further cooperate with this research through various channels such as project cooperation, work partners, telephone calls, emails and field interviews. Furthermore, the authors designed the questionnaire based on the literature review and semi-structured interviews, and conducted a small trial with 30 OSC practitioners. Based on the validation tests (Facility Index (FI) and Discrimination Coefficient (DC) proposed in [76]) of the questionnaires using the data collected from the trial, further improvement and confirmation were made on the questionnaire. At last, the authors distributed the final questionnaires to a larger sample of construction practitioners and collected the completed questionnaires back.

In the empirical analysis phase, this study got the values of DP, MR, PI, NP and TV by calculating the average of their corresponding items, and conducted adequate statistical validation test. Then the authors used Hierarchical Regression Analysis and Bootstrap-based Moderated Mediating Model to test the hypotheses by IBM SPSS Statistics 20. Variables of each level were analyzed separately by Hierarchical Regression and the differences in regression results were found. Causal Stepwise Regression method [77] was used for prediction, applicable to the model with only one mediator variable, and finding significant variables for the dependent variable and excluding those variables that are not significant by certain criteria. Hierarchical regression can retain all the important variables 
under theoretical analysis, and is not completely subject to the data quality with stronger explanatory power [78]. Moreover, the Bootstrap method repairs the defects of the Causal Stepwise Regression in the mediating effect test procedure, which can be used to test the complex mediating effect $[77,79]$. Bootstrap has been recognized by researchers as one method in mediation analysis.

\subsection{Questionnaire Design}

The questionnaire structure was divided into three levels. The first construct is the scope of the research content, including the research object (the diffusion of technology innovation), the external environment (the dual regulation of market and government), the diffusion subjects (the overall strength of a company) and the diffusion object (the characteristics of technology innovation). The sub-constructs, including DP, MR, PI, NP and TV correspondingly, were used to reflect and explain the construct above. For the third level, 30 questions were developed to measure the thirty corresponding variables related to the four constructs in the hypotheses. The specific measurements of the relevant variables are shown in Table 1 . The items of the questionnaire in this study were based on the five-point Likert scale system (some objective items required detailed information or options). The scale ranges from 1 to 5, where 1 represents strong disagreement, 2 represents disagreement, 3 represents neutral, 4 represents agreement and 5 represents strong agreement.

Table 1. Summary of Constructs, Sub-Constructs and Indicators.

\begin{tabular}{|c|c|c|c|}
\hline Constructs & Sub-Constructs & Items/Indicators & Justification \\
\hline $\begin{array}{c}\text { Technology Innovation } \\
\text { Diffusion }\end{array}$ & DP & $\begin{array}{l}\text { DP1 Economic Performance } \\
\text { DP2 Environmental Performance } \\
\text { DP3 Social Performance }\end{array}$ & {$[80]$} \\
\hline \multirow[t]{2}{*}{ External Environment } & MR & $\begin{array}{l}\text { MR1 Cooperation Relationship } \\
\text { MR2 Competition Relationship } \\
\text { MR3 Cooperation Strength } \\
\text { MR4 Cooperation Time } \\
\text { MR5 Cooperation Quality } \\
\text { MR6 Cooperation Quantity }\end{array}$ & $\begin{array}{l}{[55] ;} \\
\text { Field interview }\end{array}$ \\
\hline & PI & $\begin{array}{l}\text { PI1 Policy Timeliness } \\
\text { PI2 Mandatory Policies } \\
\text { PI3 Encouraging Policies } \\
\text { PI4 Supporting Efforts }\end{array}$ & $\begin{array}{l}{[58,59] ;} \\
\text { Field interview }\end{array}$ \\
\hline Company's Strength & NP & $\begin{array}{l}\text { NP1 Difficult To Imitate } \\
\text { NP2 Decision Influence } \\
\text { NP3 Exchange Prestige } \\
\text { NP4 Leading Technology }\end{array}$ & {$[81,82]$} \\
\hline $\begin{array}{l}\text { Characteristic of } \\
\text { Innovation }\end{array}$ & $\mathrm{TV}$ & $\begin{array}{l}\text { TV1 Operation Difficulty } \\
\text { TV2 Universal Interface } \\
\text { TV3 Implementation Cost }\end{array}$ & $\begin{array}{l}{[5,72] ;} \\
\text { Field interview }\end{array}$ \\
\hline
\end{tabular}

\subsection{Data Collection}

In order to avoid information distortion, the preliminary questionnaire was delivered to 30 OSC practitioners with substantial OSC experience. According to the feedback, the ambiguous wording and incomplete description on the questions were modified. The OSCTI has various forms, and different companies have different technical capacities, different degrees of acceptance and understanding for OSCTI. Therefore, data from a single company or an individual project might not be representative resulting in bias. To include more data from as many companies as possible while minimizing the unqualified responses, this study collected data through semi-structured interviews, e-mails and online questionnaires using snowball sampling. 236 questionnaires were distributed, and 198 questionnaires were returned. Among them, 37 respondents did not have experience in OSC project or the time used 
in answering the questions was less than $60 \mathrm{~s}$ (online questionnaire). Therefore, those 37 respondents were excluded from the analysis, making the final number of valid questionnaires 151 and the effective response rate of $76 \%$.

The collected data spans more than 100 construction companies with different types, natures and sizes, which will be listed in next section in detail. These construction companies are mainly engaged in off-site housing, covering the entire supply chain of design, component production, construction, decoration, consulting and development. Most of them are the leaders in the China's OSC industry, such as Vanke, Broad, Country Garden and CSCEC (China State Construction Engineering Corporation), which ensure the industry representativeness and reliability of the survey data and avoid the deviation of single data sources.

\section{Data Analysis}

\subsection{Basic Information}

First, a main information statistics was made on the valid data collected, as shown in Table 2. Among all respondents, senior managers, middle managers, technicians, R\&D personnel and other personnel account for $19.9 \%, 44.4 \%, 27.8 \%, 4 \%$ and $4 \%$ respectively. They come from 119 construction companies of 40 cities in China. The regions, company characteristics (including prefabrication experience, company nature, company type and company size) and the ranks of the respondents basically cover different situations in which OSCTI is diffused, ensuring the heterogeneity of the overall sample. The correlation coefficients between variables are summarized in Table 3, indicating the independence of variables is good.

Table 2. Main Information Statistics.

\begin{tabular}{cccc}
\hline Variable & Category & Number & Percentage (\%) \\
\hline \multirow{2}{*}{ Prefabrication Experience (PE) } & $0-1$ years & 64 & $42.4 \%$ \\
& $1-3$ years & 35 & $23.2 \%$ \\
& $3-5$ years & 23 & $15.2 \%$ \\
& $5-10$ years & 19 & $12.6 \%$ \\
Company Nature (CN) & More than 10 years & 10 & $6.6 \%$ \\
\hline & Foreign Company & 2 & $1.3 \%$ \\
& Joint Venture & 9 & $6.0 \%$ \\
& State-owned Company & 51 & $33.8 \%$ \\
& Private Company & 79 & $52.3 \%$ \\
& Else & 10 & $6.6 \%$ \\
\hline \multirow{2}{*}{ Company Type (CT) } & Development Company & 85 & $56.3 \%$ \\
& Construction Company & 30 & $19.9 \%$ \\
& Component Company & 2 & $1.3 \%$ \\
& Consulting/Design Company & 26 & $17.2 \%$ \\
& Else & 8 & $5.3 \%$ \\
\hline \multirow{2}{*}{ Company Size (CS) } & Less than 50 people & 9 & $6.0 \%$ \\
& $50-100$ people & 12 & $7.9 \%$ \\
& $100-200$ people & 15 & $9.9 \%$ \\
& 200-500 people & 35 & $23.2 \%$ \\
& More than 500 people & 80 & $53.0 \%$ \\
\hline
\end{tabular}


Table 3. Person Correlation Coefficients.

\begin{tabular}{cccccccccc}
\hline & DP & MR & PI & NP & TV & PE & CN & CT & CS \\
\hline DP & 1 & & & & & & & & \\
MR & $0.371^{* *}$ & 1 & & & & & & & \\
PI & $0.339^{* *}$ & $0.381^{* *}$ & 1 & & & & & & \\
NP & $0.469^{* *}$ & $0.309^{* *}$ & 0.061 & 1 & & & & \\
TV & 0.090 & $0.320^{* *}$ & $0.398^{* *}$ & $0.189^{*}$ & 1 & & & \\
PE & -0.005 & -0.068 & -0.109 & $0.213^{* *}$ & -0.024 & 1 & & \\
CN & -0.104 & 0.006 & 0.073 & -0.015 & -0.004 & 0.079 & 1 & \\
CT & 0.013 & $0.193^{*}$ & -0.084 & 0.104 & -0.077 & -0.003 & -0.053 & 1 \\
CS & -0.065 & -0.059 & 0.100 & -0.057 & 0.057 & $0.189 *$ & -0.021 & $-0.196^{*}$ & 1 \\
\hline \multicolumn{7}{c}{ **0.01 (Bilateral) significant *0.05 (Bilateral) significant. }
\end{tabular}

\subsection{Validation of Data}

Firstly, the general descriptive statistical parameters of each variable are obtained in Table 4 . The three types of parameters [76] are: central tendency measures (mean, median, mode and sum), dispersion measures (standard deviation, variance, amplitude, minimum, maximum and error of mean) and sampling distribution (asymmetry and kurtosis). The central tendency and dispersion indicators of each variable further verify that the mean is well represented. Therefore, this study uses the values of DP, MR, PI, NP and TV by calculating whether the mean of their corresponding items is reasonable. Moreover, the data distributions for all variables have unilateral values, extending into the negative zone, indicating that the sample data does not satisfy normal distribution.

Table 4. Results of the Descriptive Statistics for the Variables.

\begin{tabular}{cccccc}
\hline Parameter & DP & MR & PI & NP & TV \\
\hline Mean & 3.709 & 3.570 & 4.205 & 3.055 & 3.861 \\
Standard Error of Mean & 0.070 & 0.078 & 0.070 & 0.090 & 0.075 \\
Median & 3.670 & 3.830 & 4.250 & 3.000 & 4.000 \\
Mode & 3.670 & 4.000 & 5.000 & 3.000 & 5.000 \\
Standard Deviation & 0.864 & 0.960 & 0.856 & 1.101 & 0.916 \\
Variance & 0.747 & 0.922 & 0.733 & 1.213 & 0.839 \\
Asymmetry & -0.746 & -0.517 & -1.431 & -0.280 & -0.647 \\
Standard Error of Asymmetry & 0.197 & 0.197 & 0.197 & 0.197 & 0.197 \\
Kurtosis & 1.137 & -0.235 & 2.583 & -0.566 & -0.085 \\
Standard Error of Kurtosis & 0.392 & 0.392 & 0.392 & 0.392 & 0.392 \\
Amplitude & 4.000 & 4.000 & 4.000 & 4.000 & 4.000 \\
Minimum & 1.000 & 1.000 & 1.000 & 1.000 & 1.000 \\
Maximum & 5.000 & 5.000 & 5.000 & 5.000 & 5.000 \\
Sum & 560.050 & 539.020 & 635.000 & 461.250 & 582.960 \\
\hline
\end{tabular}

Furthermore, the authors judge the adaption and eligibility of the questions through FI and DC [76]. It was found that all of the questions are located in a band from $60-90 \%$ of FI and more than 0.5 of DC. Therefore, the items used in the questionnaire were set properly, without serious problems, and the reliability test of the obtained data can be performed next.

The reliability test was done using the internal consistency method, with the results shown in Table 5. Cronbach's $\alpha$ for all variables was greater than 0.70 , indicating that the internal consistency of the sample data is acceptable.

The scale in this study was drafted on the basis of mature scale, supplemented and improved through the trial study, ensuring the content validity. The measurement of the aggregated validity can be comprehensively determined using three indicators [83]: the standardized factor loading, the Combination Reliability (CR) and the Average Variance Extraction (AVE). The results of the validity test are summarized in Table 5, which indicate that the intrinsic quality of the model is sound. 
The square roots of the AVEs of all sub-constructs are listed on the diagonal of Table 6, and the data in the left of the main diagonal are the correlation coefficients between the two. By comparison, it was found that the square roots of the AVEs were all greater than the correlation coefficients, indicating the discriminant validity was good.

Table 5. Reliability and Aggregate Validity Test Results. CR: Combination Reliability; AVE: Average Variance Extraction.

\begin{tabular}{ccccc}
\hline Item Number & Indicator Loading & CR & AVE & Cronbach's $\alpha$ \\
\hline DP1 & 0.832 & & & \\
DP2 & 0.530 & 0.681 & 0.427 & 0.737 \\
DP3 & 0.554 & & & \\
MR1 & 0.695 & & & \\
MR2 & 0.627 & & & \\
MR3 & 0.837 & 0.900 & 0.604 & \\
MR4 & 0.843 & & & \\
MR5 & 0.873 & & & \\
MR6 & 0.758 & & & \\
P1 & 0.836 & & & \\
PI2 & 0.756 & 0.881 & 0.649 & \\
PI3 & 0.838 & & & \\
PI4 & 0.790 & & & \\
NP1 & 0.715 & & & \\
NP2 & 0.754 & 0.894 & 0.682 & \\
NP3 & 0.918 & & & \\
NP4 & 0.897 & & & \\
TV1 & 0.810 & \multirow{2}{*}{0.767} \\
TV2 & 0.749 & 0.803 & 0.577 & \\
TV3 & 0.716 & & &
\end{tabular}

Table 6. Discriminant Validity Test.

\begin{tabular}{cccccc}
\hline Variables & DP & MR & PI & NP & TV \\
\hline DP & 0.653 & & & & \\
MR & $0.371^{* *}$ & 0.777 & & & \\
PI & $0.339^{* *}$ & $0.381^{* *}$ & 0.806 & & \\
NP & $0.469^{* *}$ & $0.309^{* *}$ & 0.061 & 0.826 & \\
TV & 0.090 & $0.320^{* *}$ & $0.398^{* *}$ & $0.189 *$ & 0.759 \\
\hline \multicolumn{7}{c}{0.01 (Bilateral) significant, ${ }^{*} 0.05$ (Bilateral) significant. }
\end{tabular}

\subsection{Common Method Bias}

All measurements in this study came from the same survey questionnaire so that the results may be affected by common method bias. To assess the extent to which common method deviations may cause problems, Harman's one-factor test [84] was used. The measurement items of DP, MR, PI, $\mathrm{NP}$ and TV were combined to make a factor analysis and tested the un-rotated results. Five factors were abstracted, and the variance contribution rate of the first factor was $33.57 \%$ (less than $40 \%$ ), indicating that the common method bias problem is not serious.

\section{Results}

\subsection{Test of Impacts of External Environment on DP}

First, taking DP as the dependent variable, the authors put the control variables (PE, CN, CT and $\mathrm{CS}$ ) into the regression model, and then put the independent variables (MR and PI) into the regression model, respectively. Model 1a and Model $1 \mathrm{~b}$ were obtained. As shown in Table 7, there is a significant positive correlation $(b=0.386, p=0.000<0.001)$ between MR and DP in Model 1a and a significant positive correlation $(b=0.369, p=0.000<0.001)$ between PI and DP in Model $1 b$. Then, MR and 
PI are put into the regression model simultaneously. In Model 1c, MR and DP are still significantly positively correlated $(b=0.282, p=0.001<0.01)$. At the same time, PI and DP are also significantly positively correlated $(b=0.255, p=0.002<0.01)$. Moreover, the significant coefficients of MR and PI on DP show that the influence degrees of MR and PI are similar, which is consistent with the immature development of OSC in China at the current stage. Therefore, H1 is supported.

Table 7. Effect of MR and PI on DP of the OSCTI.

\begin{tabular}{|c|c|c|c|c|c|c|}
\hline \multirow{3}{*}{ Variables } & \multicolumn{6}{|c|}{ DP } \\
\hline & \multicolumn{2}{|c|}{ Model 1a } & \multicolumn{2}{|c|}{ Model 1b } & \multicolumn{2}{|c|}{ Model 1c } \\
\hline & $\mathbf{b}$ & $p$ & $\mathbf{b}$ & $p$ & $\mathbf{b}$ & $p$ \\
\hline $\mathrm{PE}$ & 0.043 & 0.582 & 0.068 & 0.391 & 0.071 & 0.352 \\
\hline $\mathrm{CN}$ & -0.116 & 0.134 & -0.138 & 0.077 & -0.135 & 0.074 \\
\hline $\mathrm{CT}$ & -0.080 & 0.313 & 0.015 & 0.849 & -0.046 & 0.558 \\
\hline CS & -0.068 & 0.389 & -0.114 & 0.156 & -0.099 & 0.205 \\
\hline MR & $0.386^{* * *}$ & 0.000 & & & $0.282^{* *}$ & 0.001 \\
\hline PI & & & $0.369^{* * *}$ & 0.000 & $0.255^{* *}$ & 0.002 \\
\hline $\mathrm{R}^{2}$ & \multicolumn{2}{|c|}{0.158} & & & \multicolumn{2}{|c|}{0.211} \\
\hline F Statistics & 5.449 & 0.000 & 4.990 & 0.000 & 6.401 & 0.000 \\
\hline
\end{tabular}

The number of construction companies in different regions reflects the distribution of OSCTI to a certain extent, which is regarded approximately as DP in this study. To further verify the conclusions of H1, the authors searched the company information authority website in China, "Qi Cha Cha", to obtain the data of construction companies in each region. Specifically, by inputting the keywords "Off-Site Construction" and "Industrialized Construction" as business scope and filtering the construction as industry, the construction companies' information in different regions can be obtained. After manual confirmation, the distribution of construction companies is shown in Figure 2. The figure shows that the number of construction companies is larger and DP of OSCTI is better in those regions with mature market environment, including, but not limited to Jiangsu, Shandong, Zhejiang, Guangdong, Sichuan, Shanghai, Beijing, etc. On the other hand, "Guiding Opinions of the General Office of the State Council on Vigorously Developing Off-Site Construction (GBF (2016) NO.71)" clearly stated that the key regions for the promotion of China's OSC are the three major urban agglomerations of the Beijing-Tianjin-Hebei, Yangtze River Delta and Pearl River Delta. A number of policies of OSC have been issued in these regions. The regional distribution by government regulation is similar to the conclusion obtained from Figure 2. Therefore, the influence significance and similarity of MR and PI on DP are verified. Furthermore, the results obtained in this part are consistent with the conclusions of the references $[5,11]$. The researchers believe that both policy and market environment are the main factors influencing the development of OSC, and they are positively related to the diffusion of OSCTI. However, due to the current immature development of OSCTI, there are some weakness for market and policy hindering the promotion of OSC.

\subsection{Mediating Effect Test of NP}

To test the effect of NP on DP, in model 2a, the variable NP is put into the regression model. As shown in Table 8, NP is significantly positively correlated with DP $(b=0.492, p=0.000)$. Then, MR and PI were used as independent variables while NP was input as a mediator variable to obtain the model 2c. At this time, the influence of MR on DP was no longer significant $(p=0.064)$, while the correlation between NP and DP remained significant $(b=0.415, p=0.000)$; thus, NP may have a mediating effect. Using the bootstrap-based mediation test [85] for further verification, the sample size was chosen as 5000. At $95 \%$ confidence interval, the result of the mediation test did not include $0(\mathrm{LLCI}=0.0418, \mathrm{ULCI}=0.2307)$, indicating that the mediating effect of NP was significant and the mediating effect was 0.1217 . In addition, since the mediator NP was controlled, the independent 
variable MR no longer had a significant effect on DP with the interval $(\mathrm{LLCI}=-0.0079, \mathrm{ULCI}=0.2725)$ including 0 . This result shows that when PI was input as an independent variable, NP played a mediating role in the influence of MR on DP, and was the only mediation variable. Therefore, $\mathrm{H} 3$ is supported.

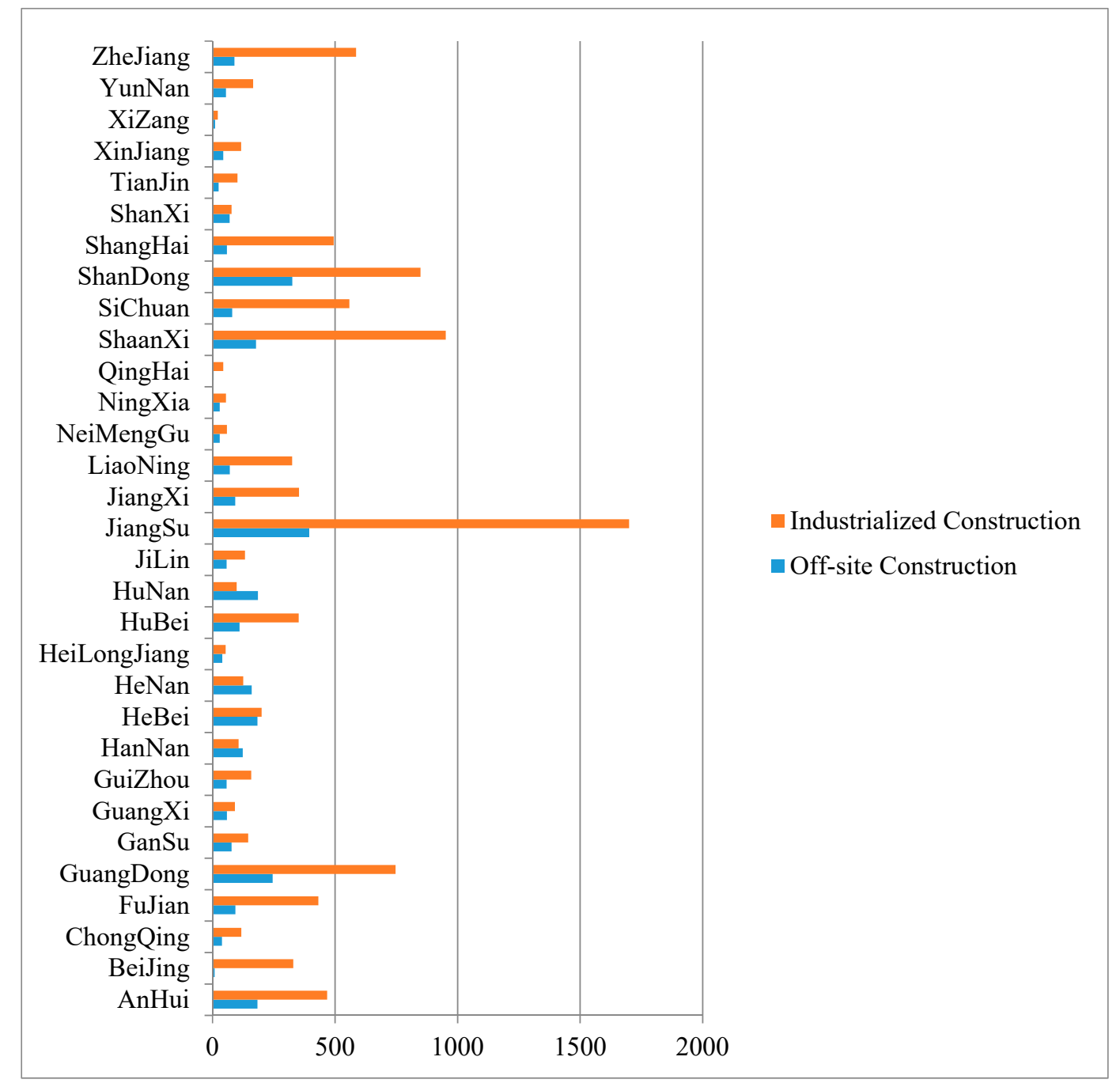

Figure 2. Distribution of construction companies in different regions in China.

Table 8. Effect of NP and PI on DP of the OSCTI.

\begin{tabular}{|c|c|c|c|c|c|c|}
\hline \multirow{3}{*}{ Variables } & \multicolumn{6}{|c|}{ DP } \\
\hline & \multicolumn{2}{|c|}{ Model 2a } & \multicolumn{2}{|c|}{ Model 2b } & \multicolumn{2}{|c|}{ Model 2c } \\
\hline & $\mathbf{b}$ & $p$ & $\mathbf{b}$ & $p$ & $\mathbf{b}$ & $p$ \\
\hline $\mathrm{PE}$ & -0.097 & 0.204 & -0.060 & 0.417 & -0.033 & 0.651 \\
\hline $\mathrm{CN}$ & -0.092 & 0.207 & -0.100 & 0.156 & -0.120 & 0.080 \\
\hline CT & -0.048 & 0.515 & -0.091 & 0.215 & -0.055 & 0.439 \\
\hline CS & -0.030 & 0.695 & -0.035 & 0.634 & -0.066 & 0.353 \\
\hline NP & $0.492 * * *$ & 0.000 & $0.409^{* * *}$ & 0.000 & $0.415^{* * *}$ & 0.000 \\
\hline MR & & & $0.256^{* *}$ & 0.001 & 0.147 & 0.064 \\
\hline PI & & & & & $0.265^{* *}$ & 0.001 \\
\hline $\mathrm{R}^{2}$ & \multicolumn{2}{|c|}{0.242} & \multicolumn{2}{|c|}{0.299} & \multicolumn{2}{|c|}{0.355} \\
\hline F Statistics & 9.269 & 0.000 & 10.220 & 0.000 & 11.244 & 0.000 \\
\hline
\end{tabular}




\subsection{Dual-Mediating Effects of NP and PI}

Based on the Model 2a, Model $2 \mathrm{~b}$ is obtained in Table 7 after the independent variable MR is introduced. At this time, the influence of MR on DP was still significant. The significance between NP and DP remained unchanged $(b=0.409, p=0.000)$; thus, NP may exist as a mediation variable, and there may be missing mediations. Furthermore, by using the bootstrap-based mediation test [85], the result of the mediation test did not include 0 (LLCI $=0.0447$, ULCI $=0.2179$ ), indicating that the mediating effect of NP was significant, and the mediating effect was 0.1166 . Moreover, after controlling the mediator variable NP, the influence of the independent variable MR on DP was still significant. The interval (LLCI $=0.0968$, ULCI $=0.3647$ ) did not include 0 ; therefore, NP played a mediating role in the influence of MR on DP, but it was not the only mediation variable.

Data analysis of the Bootstrap test shows that the joint mediating effect of NP and PI was significant $(0.1151,0.3406)$, and the effect value was 0.215 ; the mediating effect of NP was significant $(0.0462,0.2187)$, and the value was 0.1182 ; the mediating effect of PI was significant $(0.0398,0.1909)$, and the value was 0.0984; while the path coefficient between NP and PI was not significant $(-0.0210$, 0.0114). Comparing the mediating roles of NP and PI, the results show that the mediating effect of NP was significantly higher than PI (the mediating effect difference is 0.0198 ). The result shows that when PI was input as a mediator variable, it played a dual mediating role with NP. That is, the impact of MR on DP was at least partially affected by NP and PI. Therefore, H2 is supported.

\subsection{Impact Test of $T V$}

In order to test the effect of TV on DP, the variable TV was put into the regression Model 4a. As shown in Table 9, TV was positively correlated with DP but not significant $(b=0.094, p=0.256$ ). The independent variables of MR and PI were put into the model $4 \mathrm{~b}$, and the direct impact of TV on DP was still not significant $(b=-0.123, p=0.138)$. However, the direction of correlation was changed. In order to test the moderating role of TV, the interaction term of MR and TV was further substituted into model 4c. To avoid multicollinearity, the indicators of MR and TV were all centralized and then multiplied correspondingly. The coefficient of the interaction term MR*TV and DP was significant $(b=0.174, p=0.023<0.05)$, indicating that TV positively moderated the influence of MR on DP, and the moderating value was $2.8 \%$.

Table 9. Moderating Effect Test of TV.

\begin{tabular}{|c|c|c|c|c|c|c|}
\hline \multirow{3}{*}{ Variables } & \multicolumn{6}{|c|}{ DP } \\
\hline & \multicolumn{2}{|c|}{ Model 4a } & \multicolumn{2}{|c|}{ Model 4b } & \multicolumn{2}{|c|}{ Model 4c } \\
\hline & b & $p$ & b & $p$ & b & $p$ \\
\hline PE & 0.021 & 0.803 & 0.074 & 0.330 & 0.077 & 0.307 \\
\hline $\mathrm{CN}$ & -0.110 & 0.185 & -0.139 & 0.065 & -0.115 & 0.122 \\
\hline $\mathrm{CT}$ & -0.001 & 0.989 & -0.057 & 0.464 & -0.048 & 0.530 \\
\hline CS & -0.074 & 0.385 & -0.097 & 0.212 & -0.110 & 0.153 \\
\hline TV & 0.094 & 0.256 & -0.123 & 0.138 & -0.145 & 0.079 \\
\hline MR & & & $0.310^{* * *}$ & 0.000 & $0.339^{* * *}$ & 0.000 \\
\hline PI & & & $0.293 * *$ & 0.001 & $0.309^{* * *}$ & 0.000 \\
\hline $\mathrm{MR}^{*} \mathrm{TV}$ & & & & & 0.174 * & 0.023 \\
\hline $\mathrm{R}^{2}$ & \multirow{2}{*}{\multicolumn{2}{|c|}{0.024}} & \multicolumn{2}{|c|}{0.223} & \multicolumn{2}{|c|}{0.251} \\
\hline$\Delta \mathrm{R}^{2}$ & & & \multicolumn{2}{|c|}{-} & \multicolumn{2}{|c|}{0.028} \\
\hline
\end{tabular}

The moderating effect of TV was further tested by the bootstrap method [85]. Whether the level of TV was low $(b=0.2042, \mathrm{SE}=0.0824,95 \% \mathrm{CI}=0.0413-0.3672)$, mean $(b=0.2650, \mathrm{SE}=0.0710,95 \% \mathrm{CI}$ $=0.1247-0.4053)$ or high $(\mathrm{b}=0.3258, \mathrm{SE}=0.1019,95 \% \mathrm{CI}=0.1243-0.5273)$, the moderating effects of TV on the relationship between MR and DP were all significant. The result can be seen in Figure 3 . 
Therefore, the direct impact of TV is not supported while the moderating role of TV is supported; that is, H4 is partly supported.

To sum up, three hypotheses ( $\mathrm{H} 1, \mathrm{H} 2$ and $\mathrm{H} 3$ ) proposed are supported, while one hypothesis (H4) is partly supported. Further analysis of the results and some new relationships found during the empirical analysis will be discussed next.

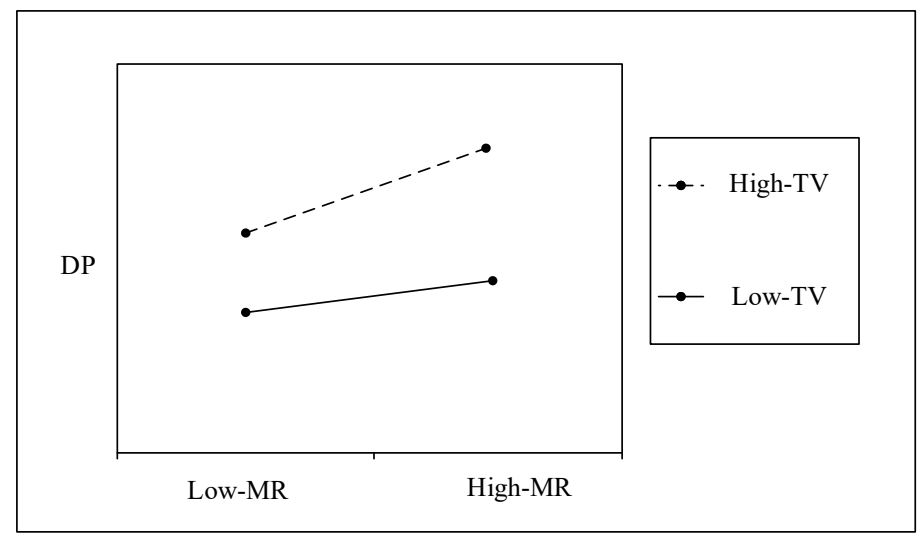

Figure 3. Moderating Role of TV on the Relationship between MR and DP.

\section{Discussions}

\subsection{Further Analysis of Dual-Mediating Effects of NP and PI}

This study initially analyzed the impacts of MR and PI on DP, considering PI as an independent variable, and found the mediating effect of NP and the moderating effect of TV. However, through the analysis above, PI also played a role in the relationship between MR and DP, constituting a dual-mediation with NP.

The MR exists in parallel with PI, which are the dual means for market and government to promote the diffusion of OSCTI. Meanwhile, MR also influences PI by the government. The better cooperation and competition by MR indicates stronger overall strength and more significant influence of the construction company in the industry. As a result, the government tends to open its subsidy policy of the OSCTI to the construction companies, which can improve the approval efficiency of matters related to OSC for the construction companies. Furthermore, the government is more inclined to invite construction companies with high-quality cooperation and competition relationships, who can use their excellent professional knowledge, high prestige and discourse power in the industry to improve the OSCTI system, to participate in the regulation development for OSC, technical specifications and related standards. In this way, the diffusion of OSCTI can be quickly and effectively promoted. Therefore, the influence of MR on DP (at least in part) plays a role through PI.

Whenever PI is used as an independent variable or a mediator variable, NP always plays a mediating role in the relationship between MR and DP. This demonstrates that the construction companies cannot be separated from technology innovation cooperation and diffusion networks, and they inevitably establish contact with other companies to form their own dynamic NP. In the market activities, OSC technology adoption decisions are always influenced by NP, and the implementation of NP affects the diffusion of OSCTI.

\subsection{In-depth Analysis of the Role of TV}

Generally, TV can increase DP and promote the diffusion of technology innovation. However, the empirical analysis in this study (model 4a) has concluded that TV does not significantly improve DP. The authors make further analysis and find this is related to the immature development of current Chines OSC market. The costs and risks of technology input are still high, and the professional ability of employees needs much improvement. Therefore, the influence of high TV on DP is positive, but not 
significant. Besides, a high versatility of OSCTI also indicates that many companies are using the technology in the market; thus, the transaction profit is lower than small number of companies' use. As a result, the opportunity for the construction companies to obtain excessive profits through this technology becomes smaller. Therefore, higher TV does not necessarily lead to more profits, that is, the direct influence of TV on DP of OSCTI is not significant.

Analysis of the moderating effects of TV showed that the direct impact of TV on DP was uncertain. The relationship between TV and DP can be positive or negative depending on the context. There may be a secondary effect of the impact of TV on DP. The analysis result in Table 10 shows that the correlations between TV / TV ${ }^{*} \mathrm{TV}$ and DP do not pass the significance test, which means that TV has no secondary effect on DP. However, it can be seen that the direct impact of TV is different from that of secondary effect which confirms the threshold effect between TV and DP. Therefore, TV does not promote or impede DP in a single direction, but the determination of the specific threshold needs to be further explored in future.

Table 10. Secondary Effect Test of TV.

\begin{tabular}{cccc}
\hline Model & $\mathbf{b}$ & $\boldsymbol{t}$ & $\boldsymbol{p}$ \\
\hline $\mathrm{PE}$ & 0.028 & 0.340 & 0.735 \\
$\mathrm{CN}$ & -0.100 & -1.212 & 0.228 \\
$\mathrm{CT}$ & -0.004 & -0.046 & 0.963 \\
$\mathrm{CS}$ & -0.052 & -0.604 & 0.547 \\
$\mathrm{TV}$ & -0.743 & -1.359 & 0.176 \\
$\mathrm{TV}^{*} \mathrm{TV}$ & 0.846 & 1.549 & 0.124 \\
\hline
\end{tabular}

\subsection{Moderated Mediating Effect of NP and PI}

Since the regression model contains both mediator and moderator variables, it is necessary to analyze the interaction between them further. Muller [86] defined the moderated mediation and the mediated moderation (the difference between them is whether the moderation occurs before or after the mediating effect), and proposed the corresponding test methods. Because they both need to test the mediation path based on different levels of moderator variables, the nature is the same as the moderated mediation; the next section only explained the moderated mediating tests [86].

\subsubsection{Moderated Mediating Effect Test of NP}

When the role of PI is not considered, the moderated mediation model based on bootstrap [85] is used to test the relationship between TV, MR, NP and DP. The results are shown in Table 11. There are significant differences in terms of TV level: low $(b=0.0653, \mathrm{SE}=0.0509,95 \% \mathrm{CI}=-0.0110-0.1890)$, the mediating effect of NP is not significant; mean ( $b=0.1116$, SE $=0.0407,95 \% \mathrm{CI}=0.0459-0.2094)$ and high $(b=0.1579, \mathrm{SE}=0.0525,95 \% \mathrm{CI}=0.0739-0.2904)$, the mediating effects of NP are significant.

Table 11. Mediating Effect Test of NP Moderated by TV.

\begin{tabular}{ccccc}
\hline \multirow{2}{*}{ Mediator Variable } & \multicolumn{3}{c}{ The Moderated Role of TV } \\
\cline { 2 - 5 } & Condition & Regression Coefficient & Standard Deviation & 95\% Confidence Interval \\
\hline NP & Low & 0.0653 & 0.0509 & {$[-0.0110,0.1890]$} \\
NP & Mean & 0.1116 & 0.0407 & {$[0.0459,0.2094]$} \\
NP & High & 0.1579 & 0.0525 & {$[0.0739,0.2904]$} \\
\hline
\end{tabular}

The authors continued to use PI as an independent variable and test the relationships between TV, MR, PI, NP and DP using a moderated mediation model based on the bootstrap. The results are shown in Table 12. There are significant differences in the mediating effect of NP by TV: low TV level $(b=0.0556$, SE $=0.0497,95 \% \mathrm{CI}=-0.0152-0.1779)$, the mediating effect of NP is not significant; mean TV level $(b=0.1187, \mathrm{SE}=0.0445,95 \% \mathrm{CI}=0.0456-0.2180)$ and high TV level $(\mathrm{b}=0.1818$, 
$\mathrm{SE}=0.0615,95 \% \mathrm{CI}=0.0788-0.3253)$, the mediating effects of NP are significant, which are the same as the above conclusions.

Table 12. Mediating Effect Test of NP Moderated by TV under PI.

\begin{tabular}{ccccc}
\hline \multirow{2}{*}{ Mediator Variable } & \multicolumn{3}{c}{ The Moderated Role of TV } \\
\cline { 2 - 5 } & Condition & Regression Coefficient & Standard Deviation & 95\% Confidence Interval \\
\hline NP & Low & 0.0556 & 0.0497 & {$[-0.0152,0.1779]$} \\
NP & Mean & 0.1187 & 0.0445 & {$[0.0456,0.2180]$} \\
NP & High & 0.1818 & 0.0615 & {$[0.0788,0.3253]$} \\
\hline
\end{tabular}

Therefore, regardless of the existence of PI, NP mediates the interactive influence of MR and TV on DP under the condition of mean and high TV levels, while this relationship is not significant under the condition of low TV level.

\subsubsection{Moderated Mediating Effect Test of PI}

The authors put PI into the model as a mediator, and test the moderated role of TV in the mediation path of PI. A mediated mediation model based on bootstrap [85] is used to test the relationship between TV, MR, PI and DP. The results are shown in Table 13.

Table 13. Mediating Effect Test of PI Moderated by TV.

\begin{tabular}{ccccc}
\hline \multirow{2}{*}{ Mediator Variable } & \multicolumn{3}{c}{ The Moderated Role of TV } \\
\cline { 2 - 5 } & Condition & Regression Coefficient & Standard Deviation & 95\% Confidence Interval \\
\hline PI & Low & 0.1224 & 0.0437 & {$[0.0506,0.2303]$} \\
PI & Mean & 0.0997 & 0.0398 & {$[0.0380,0.1998]$} \\
PI & High & 0.0771 & 0.0564 & {$[-0.0111,0.2217]$} \\
\hline
\end{tabular}

There are significant differences in terms of TV: for low TV level $(b=0.1224, \mathrm{SE}=0.0437,95 \% \mathrm{CI}=$ $0.0-0.2303)$ and mean TV level $(b=0.0997, \mathrm{SE}=0.0398,95 \% \mathrm{CI}=0.0-0.1998)$, the mediating effects of PI are significant, while for high TV level $(b=0.0771, \mathrm{SE}=0.0564,95 \% \mathrm{CI}=-0.0111-0.2217)$, the mediating effect of PI is not significant. That is to say, under the conditions of low and mean TV level, PI mediates the interaction between MR and TV on DP, while this relationship is not significant under high TV level.

\section{Conclusions}

This study surveyed more than 100 Chinese construction companies across the industry and obtained the data through a questionnaire, after a series of validation tests (FI and DC for questions, reliability and validity for data). The authors explored the impacts of external environment (including both market regulation and policy intervention), diffusion subject (represented by network power) and diffusion object (represented by technical versatility) on diffusion performance and the indirect roles of policy intervention, network power and technical versatility, through Hierarchical Regression and Bootstrap-based mediation effect analysis methods. The research confirmed three hypotheses, specifically: (1) external environment has a significant positive impact on diffusion performance, with similar influence degree of market regulation and policy intervention, which is consistent with previous studies; (2) policy intervention plays a significant mediating role in the relationship between market regulation and diffusion performance; (3) network power has a significant positive impact on diffusion performance and plays a mediating role in the relationship between market regulation and diffusion performance. However, the results partly supported $\mathrm{H} 4$, that is, technical versatility plays a significant moderating role in the relationship between market regulation and diffusion performance but has weak impact on diffusion performance. Moreover, this paper concluded the moderated mediating effects of network power and policy intervention in different contexts. 
Based on the conclusions above, the authors propose corresponding suggestions for the construction companies and government authorities, respectively: (1) for the construction companies, continuously strengthening close cooperation and healthy competition with other companies in the industry is necessary, to form high-quality cooperation and competitive links under market regulation, and to enhance the overall performance of technological diffusion. They should strive to improve their control and influence in the industry, to enhance network power and to lead the direction and rhythm of OSCTI and its diffusion. In addition, they had better actively promote the establishment of a generic technical system and the versatility of OSCTI to promote the large-scale diffusion and the rapid development of OSC. (2) For government authorities and industry associations, they should focus on the norms and standards of OSCTI, encourage the establishment of a generic technical system and use policy incentives to promote the technology diffusion on the premise that OSCTI is mature and stable after the market verification. They rationally regulate the speed, depth and breadth of the diffusion process at the current stage, but should appropriately weaken the administrative intervention, and mainly rely on market regulation and independent choice of the construction companies in the future.

This study firstly verified the significant direct impacts of the external environment (including both market regulation and policy intervention) on diffusion performance and similar influence of market regulation and policy intervention, which is consistent with the immature development of China's OSC. Secondly, policy intervention also played a dual-mediating role with network power in the relationship between market regulation and diffusion performance. Moreover, the moderating role of technical versatility in the relationship between market regulation and diffusion performance is significant; however, its direct influence on diffusion performance is weak, without secondary effect. Moreover, the moderated mediating effects of network power and policy intervention on technical versatility in different contexts are explored. Therefore, the external environment, the diffusion subject and the diffusion object play critical but different roles on diffusion performance. The conclusions theoretically identify the influence mechanism of different factors on the diffusion of OSCTI, expand the research scope of OSCTI and enrich the application of technology innovation diffusion in the field of OSC. Practically, the conclusions provide corresponding suggestions for construction companies and government, contributing to promote the effective diffusion of mature OSCTI. The effective diffusion of OSCTI contributes to the sustainable development of the construction industry, achieving economic, social and environmental sustainability.

However, there are still some limitations to this study. The first is that the sample size is not large enough, although 151 meet the basic requirements of statistical analysis. A large sample can better verify the validity of the model and the persuasiveness of the conclusions. In addition, this study is aimed at the China's OSC market, which has a uniqueness of the current stage. Therefore, certain parameters should be adjusted according to actual conditions when applied to other countries, industries or time periods. In the future, the sample data spectrum should be expanded. Besides, the comparative analysis of different countries or industries and the longitudinal evolution of the time dimension may also be examined.

Author Contributions: Conceptualization, Y.D. and Z.Z.; Methodology, Y.D., X.X. and X.L.; Software, Investigation and Original Draft Preparation, Y.D.; Supervision, X.X., Z.Z. and X.L.; Funding Acquisition, X.X. and Z.Z.

Funding: This research was funded by the National Key R\&D Program of China (grant number 2016YFC0701800 and 2016YFC0701808) and the National Natural Science Foundation of China (NSFC) (grant number 71671053, 71771067 and 71841024 and the National Social Science Fund of China (grant number 18ZDA043).

Conflicts of Interest: The authors declare no conflict of interest. 


\section{Abbreviations}

$\begin{array}{ll}\text { Abbr. } & \text { Meaning } \\ \text { MR } & \text { Market Regulation } \\ \text { PI } & \text { Policy Intervention } \\ \text { EE } & \text { External Environment, including both market regulation and policy intervention } \\ \text { NP } & \text { Network Power } \\ \text { TV } & \text { Technical Versatility } \\ \text { DP } & \text { Diffusion Performance } \\ \text { OSC } & \text { Off-Site Construction } \\ \text { OSCTI } & \text { Off-Site Construction Technology Innovation }\end{array}$

\section{References}

1. Kuo, T.C.; Hsu, C.W.; Li, J.Y. Developing a green supplier selection model by using the DANP with VIKOR. Sustainability 2015, 7, 1661-1689. [CrossRef]

2. Medineckiene, M.; Turskis, Z.; Zavadskas, E.K. Sustainable construction taking into account the building impact on the environment. J. Environ. Eng. Landsc. Manag. 2010, 18, 118-127. [CrossRef]

3. Miyatake, Y. Technology Development and Sustainable Construction. J. Manag. Eng. 1996, $12,23-27$. [CrossRef]

4. Liu, Y.; Xiao, X.; Zikhali, P.; Lv, Y. Carbon Emissions in China: A Spatial Econometric Analysis at the Regional Level. Sustainability 2014, 6, 6005-6023. [CrossRef]

5. Mao, C.; Shen, Q.; Pan, W.; Ye, K. Major Barriers to Off-Site Construction: The Developers' Perspective in China. J. Manag. Eng. 2015, 31, 4014043. [CrossRef]

6. Said, H.; Bartusiak, J. Regional Competition Analysis of Industrialized Homebuilding Industry. J. Constr. Eng. Manag. 2018, 144, 04017108. [CrossRef]

7. Gunawardena, T.; Ngo, T.; Mendis, P.; Alfano, J. Innovative Flexible Structural System Using Prefabricated Modules. J. Archit. Eng. 2016, 22, 5016003. [CrossRef]

8. Zhong, R.Y.; Yi, P.; Fan, X.; Ji, F.; Zou, W.; Hao, L.; Ng, S.T.; Lu, W.; Shen, G.Q.P.; Huang, G.Q. Prefabricated construction enabled by the Internet-of-Things. Autom. Constr. 2017, 76, 59-70. [CrossRef]

9. Gan, X.; Chang, R.; Jian, Z.; Tao, W.; Zillante, G. Barriers to the transition towards Off-site construction in China: An Interpretive Structural Modeling approach. J. Clean. Prod. 2018, 197, 8-18. [CrossRef]

10. Khaleghian, H.; Shan, Y.; Lewis, P. A Case Study of Productivity Improvement by Electrical Prefabrication. In Proceedings of the Construction Research Congress, San Juan, PR, USA, 31 May-2 June 2016; pp. 1753-1761.

11. Jiang, R.; Mao, C.; Hou, L.; Wu, C.; Tan, J. A SWOT Analysis for Promoting Off-site Construction under the Backdrop of China's New Urbanisation. J. Clean. Prod. 2018, 173, 225-234. [CrossRef]

12. Zhai, Y.; Zhong, R.Y.; Li, Z.; Huang, G. Production lead-time hedging and coordination in prefabricated construction supply chain management. Int. J. Prod. Res. 2016, 55, 3984-4002. [CrossRef]

13. Korkmaz, K.A.; Karahan, A.E. Investigation of Seismic Behavior and Infill Wall Effects for Prefabricated Industrial Buildings in Turkey. J. Perform. Constr. Facil. 2011, 25, 158-171. [CrossRef]

14. Stoneman, P. The Economic Analysis of Technological Change; Oxford University Press: Oxford, UK, 1983.

15. Rogers, E.M. Diffusion of Innovations: Modifications of a Model for Telecommunications. Die Diffusion von Innovationen in der Telekommunikation 1995, 17, 25-38.

16. Lindsey, C.W. Transfer of Technology to the ASEAN Region by U.S. Transnational Corporations. Asean Econ. Bull. 1986, 3, 225-247. [CrossRef]

17. Hong, J.; Shen, G.Q.; Li, Z.; Zhang, B.; Zhang, W. Barriers to Promoting Prefabricated Construction in China: A Cost-Benefit Analysis. J. Clean. Prod. 2018, 172, 649-660. [CrossRef]

18. Cooper, R.B.; Zmud, R.W. Information Technology Implementation Research: A Technological Diffusion Approach. Manage. Sci. 1990, 36, 123-139. [CrossRef]

19. Wang, H.; Huang, C.; Cui, Y.; Zhang, Y. Experimental study on the characteristics of secondary airflow device in a large enclosed space building. Energy Build. 2018, 166, 347-357. [CrossRef]

20. Shank, N. A review of the role of cost-benefit analyses in 2-1-1 diffusion. Am. J. Prev. Med. 2012, 43, S497-S505. [CrossRef] 
21. Kamat, V.R.; Martinez, J.C. Scene Graph and Frame Update Algorithms for Smooth and Scalable 3D Visualization of Simulated Construction Operations. Comput. Civ. Infrastruct. Eng. 2010, 17, 228-245. [CrossRef]

22. Chau, K.W.; Cao, Y.; Anson, M.; Zhang, J. Application of data warehouse and Decision Support System in construction management. Autom. Constr. 2003, 12, 213-224. [CrossRef]

23. DanielCastro-Lacouture, J.; Skibniewski, M. Applicability of e-Work models for the automation of construction materials management systems. Prod. Plan. Control 2003, 14, 789-797. [CrossRef]

24. Dawood, N.; Sriprasert, E.; Mallasi, Z.; Hobbs, B. Development of an integrated information resource base for 4D/VR construction processes simulation. Autom. Constr. 2003, 12, 123-131. [CrossRef]

25. Duxson, P.; Provis, J.L.; Lukey, G.C.; Van Deventer, J.S.J. The role of inorganic polymer technology in the development of 'green concrete'. Cem. Concr. Res. 2007, 37, 1590-1597. [CrossRef]

26. Pomianowski, M.; Heiselberg, P.; Zhang, Y. Review of thermal energy storage technologies based on PCM application in buildings. Energy Build. 2013, 67, 56-69. [CrossRef]

27. Ryan, P.C.; O'Connor, A. Comparing the durability of self-compacting concretes and conventionally vibrated concretes in chloride rich environments. Constr. Build. Mater. 2016, 120, 504-513. [CrossRef]

28. Arjunan, A. Acoustic Absorption of Passive Destructive Interference Cavities. Mater. Today Commun. 2018, 19,68-75. [CrossRef]

29. Arun Arjunan Martin English, Mark Stanford and Paul Lister, C.W. A computationally-efficient numerical model to characterize the noise behavior of metal-framed walls. Metals 2015, 5, 1414-1431. [CrossRef]

30. Arjunan, A.; Wang, C.J.; Mynors, D.J.; Yahiaoui, K.; Morgan, T.; English, M. Thermal efficiency analysis of slotted steel studs in double leaf partition walls using FEM and experimental tests. In Proceedings of the Nafems World Congress, Salzburg, Austria, 9-12 June 2013.

31. Arjunan, A.; Wang, C.J.; Yahiaoui, K.; Mynors, D.J.; Morgan, T.; Nguyen, V.B.; English, M. Development of a 3D finite element acoustic model to predict the sound reduction index of stud based double-leaf walls. $J$. Sound Vib. 2014, 333, 6140-6155. [CrossRef]

32. Wang, H.J.; Zhang, J.P.; Chau, K.W.; Anson, M. 4D dynamic management for construction planning and resource utilization is. Autom. Constr. 2004, 13, 575-589. [CrossRef]

33. Kamat; Martinez, V.R.; Julio, C. Visualizing Simulated Construction Operations in 3D. J. Comput. Civ. Eng. 2001, 15, 329-337. [CrossRef]

34. Chau, K.W.; Anson, M.; Saram, D.D. De 4D dynamic construction management and visualization software: 2. Site trial. Autom. Constr. 2005, 14, 525-536. [CrossRef]

35. Esmaeili, B.; Hallowell, M.R. Diffusion of Safety Innovations in the Construction Industry. J. Constr. Eng. Manag. 2017, 138, 955-963. [CrossRef]

36. Rose, T.M.; Manley, K. Measurement Constructs to Explore Innovation Diffusion in Construction. Available online: http:/ / eprints.qut.edu.au/55382/4/55382.pdf (accessed on 18 December 2018).

37. Gordon, M.B.; Laguna, M.F.; Gonçalves, S.; Iglesias, J.R. Adoption of innovations with contrarian agents and repentance. Phys. A Stat. Mech. Its Appl. 2017, 486, 192-205. [CrossRef]

38. Mitropoulos, P.; Tatum, C.B. Technology Adoption Decisions in Construction Organizations. J. Constr. Eng. Manag. 1999, 125, 330-338. [CrossRef]

39. Slaughter, E.S. Models of Construction Innovation. J. Constr. Eng. Manag. 1998, 124, 226-231. [CrossRef]

40. Toole, T.M. Uncertainty and Home Builders' Adoption of Technological Innovations. J. Constr. Eng. Manag. 1998, 124, 323-332. [CrossRef]

41. Beise, M. Lead markets: Country-specific drivers of the global diffusion of innovations. Res. Policy 2004, 33, 997-1018. [CrossRef]

42. Suprun, E.V.; Stewart, R.A. Construction innovation diffusion in the Russian Federation. Constr. Innov. 2015, 15, 278-312. [CrossRef]

43. Vastag, G. Revisiting ISO 14000 Diffusion: A New “Look" at the Drivers of Certification. Prod. Oper. Manag. 2009, 13, 260-267. [CrossRef]

44. Kale, S.; Arditi, D. Diffusion of Computer Aided Design Technology in Architectural Design Practice. J. Constr. Eng. Manag. 2005, 131, 1135-1141. [CrossRef]

45. Mansfield, E.; Rapoport, J.; Romeo, A.; Wagner, S.; Beardsley, G. Social and Private Rates of Return from Industrial Innovations*. Q. J. Econ. 1977, 91, 221-240. [CrossRef] 
46. Beck, R.; Beimborn, D.; Weitzel, T.; König, W. Network effects as drivers of individual technology adoption: Analyzing adoption and diffusion of mobile communication services. Inf. Syst. Front. 2008, 10, 415-429. [CrossRef]

47. Van Eck, P.S.; Jager, W.; Leeflang, P.S.H. Opinion Leaders' Role in Innovation Diffusion: A Simulation Study. J. Prod. Innov. Manag. 2011, 28, 187-203.

48. Rogers, E.M. New Product Adoption and Diffusion. J. Consum. Res. 1976, 2, 290. [CrossRef]

49. Abramovsky, L.; Simpson, H. Geographic proximity and firm-university innovation linkages: Evidence from Great Britain. J. Econ. Geogr. 2011, 11, 949-977. [CrossRef]

50. Wu, A.H.; Wang, Z.; Chen, S. Impact of specific investments, governance mechanisms and behaviors on the performance of cooperative innovation projects. Int. J. Proj. Manag. 2017, 35, 504-515. [CrossRef]

51. Gil, R.; Ruzzier, C.A. The Impact of Competition on "Make-or-Buy" Decisions: Evidence from the Spanish Local TV Industry. Manag. Sci. 2018, 64, 1121-1135. [CrossRef]

52. Yang, S.A.; Birge, J.R.; Parker, R.P. The Supply Chain Effects of Bankruptcy. Manag. Sci. 2015, 61, $2320-2338$. [CrossRef]

53. Palmatier, R.W.; Dant, R.P.; Grewal, D. A Comparative Longitudinal Analysis of Theoretical Perspectives of Interorganizational Relationship Performance. J. Mark. 2007, 71, 172-194. [CrossRef]

54. Gibbons, D.E. Interorganizational Network Structures and Diffusion of Information Through a Health System. Am. J. Public Health 2007, 97, 1684-1692. [CrossRef]

55. Said, H. Modeling and Likelihood Prediction of Prefabrication Feasibility for Electrical Construction Firms. J. Constr. Eng. Manag. 2016, 142, 4015071. [CrossRef]

56. Gang, L.; Du, Z.T. The Identified Model of the Strength of Competition-Cooperation Relationship between Enterprises. In Proceedings of the WRI Global Congress on Intelligent Systems, Xiamen, China, 19-21 May 2009.

57. Dacin, M.T.; Goodstein, J.; Scott, W.R. Institutional Theory and Institutional Change: Introduction to the Special Research Forum. Acad. Manag. J. 2002, 45, 43-56. [CrossRef]

58. Jaffe, A.B.; Newell, R.G.; Stavins, R.N. A tale of two market failures: Technology and environmental policy. Ecol. Econ. 2005, 54, 164-174. [CrossRef]

59. Koebel, C.T.; Mccoy, A.P.; Sanderford, A.R.; Franck, C.T.; Keefe, M.J. Diffusion of green building technologies in new housing construction «. Energy Build. 2015, 97, 175-185. [CrossRef]

60. Dehwah, A.H.A.; Asif, M.; Rahman, M.T. Prospects of PV Application in Unregulated Building Rooftops in Developing Countries: A Perspective from Saudi Arabia. Energy Build. 2018, 171, 76-87. [CrossRef]

61. Lybbert, T.J.; Sumner, D.A. Agricultural technologies for climate change in developing countries: Policy options for innovation and technology diffusion. Food Policy 2016, 37, 114-123. [CrossRef]

62. Jimenez, M.; Franco, C.J.; Dyner, I. Diffusion of renewable energy technologies: The need for policy in Colombia. Energy 2016, 111, 818-829. [CrossRef]

63. Chu, Z.; Xu, J.; Lai, F.; Collins, B.J. Institutional Theory and Environmental Pressures: The Moderating Effect of Market Uncertainty on Innovation and Firm Performance. IEEE Trans. Eng. Manag. 2018, 65, 392-403. [CrossRef]

64. Yang, P.; Fu, P.H. The Cooperation and Competition Mechanism of Supply Chain Based on Evolutionary Game Theory; Springer: Amsterdam, The Netherlands, 2012.

65. Wolfe, A.W. Social Network Analysis: Methods and Applications. Am. Ethnol. 2010, 24, 219-220. [CrossRef]

66. Krause, J.; Croft, D.P.; James, R. Social network theory in the behavioural sciences: Potential applications. Behav. Ecol. Sociobiol. 2007, 62, 15-27. [CrossRef]

67. Sih, A.; Hanser, S.F.; Mchugh, K.A. Social network theory: New insights and issues for behavioral ecologists. Behav. Ecol. Sociobiol. 2009, 63, 975-988. [CrossRef]

68. March, J.G. Exploration and Exploitation in Organizational Learning. Organ. Sci. 1991, 2, 71-87. [CrossRef]

69. Grewal, D.S. Network Power:The Social Dynamics of Globalization; Yale University Press: New Haven, CT, USA, 2008.

70. Flynn, L.R.; Goldsmith, R.E.; Eastman, J.K. Opinion Leaders and Opinion Seekers: Two New Measurement Scales. J. Acad. Mark. Sci. 1996, 24, 137. [CrossRef]

71. Zhou, H.; Zhou, X.; Wang, Z.; Zhang, X. Research on Network Marketing of Real Estate Enterprises; IEEE: Piscataway, PA, USA, 2010; pp. 3048-3051. 
72. Mohaghegh, Z.; Kazemi, R.; Mosleh, A. Incorporating organizational factors into Probabilistic Risk Assessment (PRA) of complex socio-technical systems: A hybrid technique formalization. Reliab. Eng. Syst. Saf. 2015, 94, 1000-1018. [CrossRef]

73. Schuh, G.; Sauer, A.; Doering, S. Managing complexity in industrial collaborations. Int. J. Prod. Res. 2008, 46, 2485-2498. [CrossRef]

74. Oppenheim, A.N. Questionnaire design, interviewing and attitude measurement. J. Mark. Res. 2000, $30,393$.

75. Doherr, H.; Christalle, E.; Kriston, L.; Härter, M.; Scholl, I. Use of the 9-item Shared Decision Making Questionnaire (SDM-Q-9 and SDM-Q-Doc) in intervention studies-A systematic review. PLoS ONE 2017, 12, e0173904. [CrossRef] [PubMed]

76. Gómez-Soberón, J.M.; Gómez-Soberón, M.C.; Corral-Higuera, R.; Arredondo-Rea, S.P.; Luis Almaral-Sánchez, J.; Guadalupe Cabrera-Covarrubias, F. Calibrating Questionnaires Evaluate, Psychometric Analysis to Knowledge; SAGE Open: Barcelona, Spain, 2013; pp. 1-14.

77. Preacher, K.J.; Hayes, A.F. Asymptotic and resampling strategies for assessing and comparing indirect effects in multiple mediator models. Behav. Res. Methods 2008, 40, 879-891. [CrossRef]

78. Wang, C.H.; Chen, K.Y.; Chen, S.C. Total quality management, market orientation and hotel performance: The moderating effects of external environmental factors. Int. J. Hosp. Manag. 2012, 31, 119-129. [CrossRef]

79. Zhao, Z.-Y.; Zhao, X.-J.; Davidson, K.; Zuo, J. A corporate social responsibility indicator system for construction enterprises. J. Clean. Prod. 2012, 29-30, 277-289. [CrossRef]

80. Ahituv, N.; Carmi, N. Measuring the power of information in organizations. Hum. Syst. Manag. 2007, 24, 231-246.

81. Leiponen, A. Control of Intellectual Assets in Client Relationships: Implications for Innovation. Strateg. Manag. J. 2008, 29, 1371-1394. [CrossRef]

82. Shen, X.L.; Cheung, C.M.K.; Lee, M.K.O. Perceived critical mass and collective intention in social media-supported small group communication. Int. J. Inf. Manag. 2013, 33, 707-715. [CrossRef]

83. Eby, L.T.; Dobbins, G.H. Collectivistic orientation in teams: An individual and group-level analysis. J. Organ. Behav. 1997, 18, 275-295. [CrossRef]

84. Hayes, A.F. Introduction to Mediation, Moderation, and Conditional Process Analysis: A Regression-Based Approach, 2nd ed.; The Guilford Press: New York, NY, USA, 2017; ISBN 1462534651.

85. Muller, D.; Judd, C.M.; Yzerbyt, V.Y. When moderation is mediated and mediation is moderated. J. Pers. Soc. Psychol. 2005, 89, 852-863. [CrossRef]

86. Preacher, K.J.; Rucker, D.D.; Hayes, A.F. Addressing Moderated Mediation Hypotheses: Theory, Methods, and Prescriptions. Multivar. Behav. Res. 2007, 42, 185-227. [CrossRef] [PubMed] 